\title{
REVIEW
}

\section{Effect of Antidiabetic Treatment on Bone}

\author{
P. JACKULIAK ${ }^{1}$, M. KUŽMA ${ }^{1}$, J. PAYER ${ }^{1}$ \\ ${ }^{1} 5^{\text {th }}$ Department of Internal Medicine, Faculty of Medicine, Comenius University Bratislava, \\ University Hospital Bratislava, Bratislava, Slovak Republic
}

Received June 11, 2019

Accepted September 4, 2019

\section{Summary}

Patients with diabetes mellitus are at an increased risk of bone fractures. Several groups of effective antidiabetic drugs are available, which are very often given in combination. The effects of these medications on bone metabolism and fracture risk must not be neglected. Commonly used antidiabetic drugs might have a positive, neutral or negative impact on skeletal health. Increased risk of fracture has been identified with use of thiazolidinediones, most definitively in women. Also treatment with sulfonylureas can have adverse effects on bone. One consequence of these findings has been greater attention to fracture outcomes in trails of new diabetes medication (incretins and SGLT-2 inhibitors). The effect of insulin on bone is discussed and the risk of fractures in patients using insulin seems to be unrelated to insulin as itself. The aim of the review is to summarize effects of antidiabetic treatment on bone - bone mineral density, fractures and bone turnover markers. The authors also try to recommend a strategy how to treat patients with diabetes mellitus regarding the risk of osteoporotic fractures. In this review the problem of how to treat osteoporosis in patient with diabetes is also discussed.

\section{Key words}

Diabetes • Osteoporosis • Fracture risk • Antidiabetic drugs

\section{Corresponding author}

P. Jackuliak, Department of Internal Medicine CUFM, University Hospital Bratislava, Ruzinovska 6, 82606 Bratislava, Slovak Republic. Email: peter.jackuliak@gmail.com

\section{Introduction}

Both osteoporosis and diabetes mellitus (DM) are prevalent diseases with significant associated morbidity and mortality. The relationship between DM and bone diseases is not clear. Recent data seem to suggest that DM and diabetic complications can lead to it, and DM can determine also the bone health (Jackuliak et al. 2014, Kurra et al. 2011). Both types of DM lead to increased risk of fracture, the most durable clinical end point of osteoporosis, which has a significant impact on morbidity and mortality as well as on the quality of life (Ferrari 2017, Nazrun et al. 2014, Raška et al. 2017). Although Type 1 diabetes (T1DM) is often associated with decreased bone mass density (BMD) values, patients with Type 2 diabetes (T2DM) usually have normal or higher than expected BMD values (Hough et al. 2016, Vestergaard 2007, Vestergaard et al. 2009).

Research over several decades has supported a primary role for insulin and insulin like growth factor-1 (IGF-1) in bone formation (Cimrmanova et al. 2017). Expression of insulin and IGF-1 receptors has been detected at different steps of osteoblast differentiation, from preosteoblast to mature ones (Fowlkes et al. 2011, Zhukouskaya et al. 2014). Moreover, insulin and IGF-1 are important factors for osteoblast linage selection, since its receptors have been found also on osteogenic bone mass surface (Zhao et al. 2014). Insulin and IGF-1 utilize many of the same cellular proteins to achieve various cellular outcomes. In addition, they are able to cross-talk with two major proosteogenic pathways that ultimately regulate Runx2 activity in osteoblasts, such as the canonical $\mathrm{Wnt} / \beta$-catenin signaling and the bone morphogenetic protein- BMP-2 pathways (Fowlkes et al. 2011).

Insulin signaling in osteoblasts is necessary for 
whole-body glucose homeostasis because it increases osteocalcin activity. To achieve this function insulin signaling in osteoblasts takes advantage of the regulation of osteoclastic bone resorption exerted by osteoblasts. Indeed, since bone resorption occurs at an acidic $\mathrm{pH}$ enough to decarboxylate proteins, osteoclasts determine the carboxylation status and function of osteocalcin. Accordingly, increasing or decreasing insulin signaling in osteoblasts promotes or hampers glucose metabolism in a bone resorption-dependent manner in mice and humans (Ferron et al. 2010, Pramojanee et al. 2014, TorresCostoso et al. 2017).

Good metabolic control of DM may improve bone status, but several anti-diabetic drugs could directly affect bone metabolism (Hayakawa et al. 2012). Over the last couple of decades also the impact of oral antidiabetic drugs (OADs) on BMD and fractures has been reported (Gilbert et al. 2015, McCarthy et al. 2016, Paul et al. 2015). Antidiabetic treatment could modulate the risk for fractures in many ways. Most studies have not explored the effect on the incidence of fractures of individual oral hypoglycemic agents, rather all oral treatments as a whole. A higher incidence of fractures has been reported in insulin-treated patients in comparison with non-insulin-treated T2DM diabetic individuals, although some studies disagree (Vestergaard et al. 2005).

Diabetes mellitus and anti-diabetic treatment should be taken into consideration when evaluating fracture risk in osteoporotic patients. In a retrospective analysis of patients with osteoporosis to assess the incidence of osteoporotic fractures and associated risk factors regarding concomitant medications only antidiabetic treatment was significantly associated with the presence of osteoporotic fracture $(F=4.260, \mathrm{p}=0.042)$, and had a considerable effect on the 10 -year risk of major osteoporotic and hip fractures (Majumdar et al. 2016, Yavropoulou et al. 2015).

This review presents of antidiabetic drugs and their effect on bone, risk of osteoporosis and fracture rates (Table 1). This issue has clinical significance because many patients receiving anti-hyperglycemic therapy are at the age range of highest fracture risk.

Table 1. Evidence of skeletal effects of diabetes medication (Lecka-Czernik 2013, Palermo et al. 2015, Schwartz 2017)

\begin{tabular}{lcccc}
\hline \multicolumn{1}{c}{ Antidiabetic drug } & \multicolumn{2}{c}{ Bone turnover markers } & BMD & Fracture Risk \\
& Bone formation & Bone resorption & & $\uparrow$ \\
\hline Insulin & $? ?$ & $? ?$ & $\uparrow$ & $\leftrightarrow$ \\
Sulfonylureas & $\uparrow / \leftrightarrow$ & $\downarrow / \leftrightarrow$ & $? ?$ \\
Metformin & $\downarrow / \leftrightarrow$ & $\downarrow / \leftrightarrow$ & $\uparrow / \leftrightarrow$ & $\uparrow / \leftrightarrow$ \\
Thiazolidinedione's & $\downarrow \downarrow / \leftrightarrow$ & $\uparrow \uparrow / \leftrightarrow$ & $\uparrow / \leftrightarrow$ & $\leftrightarrow$ \\
GLP-1 receptor agonists & $\leftrightarrow$ & $\downarrow \downarrow$ & $? ?$ & $\uparrow ?$ \\
DPP-4 inhibitors & $\downarrow / \leftrightarrow$ & $\leftrightarrow$ & $\leftrightarrow$ & $\uparrow / \leftrightarrow$ \\
$S G L T-2$ inhibitors & $\leftrightarrow$ & $\leftrightarrow$ & $\uparrow / \leftrightarrow$
\end{tabular}

\section{Metformin}

Metformin is the most commonly oral antidiabetic drug (OAD) used to increase insulin sensitivity in patients with DM. Metformin has been shown to increase osteoblast proliferation and differentiation and also augments type 1 collagen formation in cell culture. In addition, it seems to inhibit adipocyte differentiation and promotes osteoblast differentiation (Molinuevo et al. 2010, Sundararaghavan et al. 2017). Several studies have documented that metformin is osteogenic in vitro (Cortizo et al. 2006). In contrast, it is necessary to say, that others studies showed no effect of metformin on the osteogenic differentiation of bone marrow-derived mesenchymal stem cells (Hegazy 2015). Interestingly, in recent in vivo and ex vivo studies with rats found that orally administered metformin improves bone regeneration and femoral microarchitecture, and increases the osteogenic potential of bone marrow progenitor cells via an increase in the expression of Runx2 and in the phosphorylation/activation of AMPK, a well-known sensor of energetic balance. Metformin can additionally prevent the in vivo and ex vivo anti-osteogenic effects of the insulin-sensitizer rosiglitazone in rats (Gu et al. 2017, Sedlinsky et al. 2011). 
Metformin treatment could also prevent the in vitro AGEs-induced decrease in osteoblastic differentiation and induction of apoptosis, in this last case by decreasing caspase-3 activity and intracellular oxidative stress (Melton et al. 2008, Russo et al. 2016).

Human studies of the Rochester cohort suggest that metformin decreases fracture risk in T2D patients (hazard ratio 0.7) (Melton et al. 2008). Although the ADOPT studies did not demonstrate beneficial effects of metformin on fracture risk (Kahn et al. 2008), they showed decreased levels of bone resorption marker CTX and, contrary to animal studies, decreased levels of bone formation marker P1NP (Zinman et al. 2010). In a large case-control study metformin utilization was also associated with a reduction in the risk of fractures (Vestergaard et al. 2005). In contrast some authors observed in their case control study no association between treatment with the insulin-sensitizing drug metformin and incident bone fractures in type 2 patients with DM (Monami et al. 2008).

In conclusion patients receiving metformin could show a lower incidence of bone fractures as a result of a lower comorbidity.

\section{Sulphonylureas}

Sulphonylureas, the potent insulin secretagogues are used as second line agents in the treatment of T2DM. Evidence regarding the detrimental effect of these drugs on bone is limited. However, by improving glycemic control, these may exert a favorable effect on bone health (Lapane et al. 2013). Sulfonylureas might have a beneficial effect through the enhancement of IGF-1 secretion. In contrast, both the ADOPT studies and the Rochester studies were unable to show that glyburide therapy has an effect on bone mass and fracture risk (Kahn et al. 2008, Melton et al. 2008). However, glyburide therapy decreased serum levels of bone formation marker P1NP in the ADOPT studies (Zinman et al. 2010).

Several observational studies have reported a neutral effect of sulfonylureas on fracture risk in patients with DM (Chandran 2017).

In 2014 was presented the first study, suggesting a possible increased fracture risk for sulfonylureas based on retrospectively analyzed data from Invalon's Medical Outcomes for Effectiveness and Economics (MORE) registry of more than 100 million individuals. A total of 99,892 adults were identified as new users of glucose- lowering drugs. The incidence of fractures was $6.8 \%$ among the total 76924 patients taking metformin, $10.9 \%$ among the 2679 taking TZDs, and $9.7 \%$ in the 15162 on sulfonylureas. Rates for other glucose-lowering agents ranged from $6.1 \%$ of 799 individuals taking incretin drugs to $10.7 \%$ of the 626 on meglitinide. The hazard ratios for fracture risk compared with metformin were 1.40 for TZDs $(P<0.0001)$ and 1.09 for sulfonylureas $(P=0.0054)$. The increase in fracture risk for the other drug classes compared with metformin did not reach statistical significance (Tucker 2014, Mehta 2014).

Sulfonylureas appear to have a beneficial or at the very least a neutral effect on fracture risk. Attention must be paid to the higher risk of hypoglycemia and the risk of falls. There is the need of further investigation on the association between sulfonylureas and the risk of fractures.

\section{Thiazolidinediones (glitazones)}

Thiazolidinediones (TZDs) increase insulin sensitivity by acting as agonists of peroxisome proliferator-activated receptor gamma (PPAR- $\gamma$ ). PPAR- $\gamma$ is expressed in stromal cells of the bone marrow, osteoblasts, and osteoclasts and plays an important role in the differentiation of precursor cells into osteoblasts (Berberoglu et al. 2010). By impairing the differentiation of osteoblast precursors, bone formation is compromised. Additional ways of TZDs action on bone are increasing adiposity of bone marrow, decreasing aromatase activity, and promoting osteoclast differentiation, all of which increase bone resorption. In a study involving PPAR- $\gamma$ knock-out mice, an increase in osteoblastogenesis has been shown in both in vivo as well as the embryonic stem cell cultures. The TZDs, when used as antidiabetic drugs (PPAR- $\gamma$ activators), convert mesenchymal stem cells to adipocytes thereby suppressing osteoblast development (Loke et al. 2009, Mieczkowska et al. 2012).

A study on postmenopausal women using rosiglitazone demonstrated an annual reduction of BMD at the trochanter and lumbar spine of $2.56 \%$ and $2.18 \%$, respectively (Berberoglu et al. 2010). BMD is compromised through an increase in bone resorption and a decrease in bone formation (Lecka-Czernik 2010). A meta-analysis exploring long-term use and risk of fractures found that fracture risk was increased in women (but not men) while using rosiglitazone or pioglitazone (Loke et al. 2009).

MSDC-0602, a new TZD analog with low 
affinity for binding and activation of PPAR $\gamma$ but whose insulin-sensitizing properties mirror those of rosiglitazone has been recently developed. It activates the nuclear receptor in osteoclasts. MSDC-0602, in contrast to rosiglitazone, minimally activates PPAR $\gamma$ and does not alter CD36 expression in the bone-resorptive cells. Consistent with this finding, rosiglitazone increases receptor activator of NF-kB ligand (RANKL)-induced osteoclast differentiation and number, whereas MSDC0602 fails to do so (Fukunaga et al. 2015).

The use of TZDs has been shown to have deleterious effects on BMD and therefore TZDs should be avoided in patients with established osteoporosis or at high risk for fracture (Mazziotti et al. 2010). Risk factors for fracture include female gender, advanced age ( $>65$ years), and longer duration of treatment.

\section{Incretin hormones}

The role of incretin hormones in T2DM therapy has recently received much attention, because of the beneficial actions of these molecules on the pancreatic islet (Marchetti et al. 2012, Whalley et al. 2011). Incretin-based therapy encompasses two classes of drugs - glucagon like peptid 1 receptor agonists (GLP-1RAs) and dipeptidyl peptidase-4 (DPP-4) inhibitors.

After food intake, bone resorption becomes unnecessary and it is consequently inhibited. This event may be mediated by gastrointestinal hormones released after meal ingestion such as GLP-1. In line with this hypothesis, the observation that parenteral feeding is associated with reduced bone mass suggests that a deficit in incretin hormones could have a certain role in bone turnover. Interestingly, some studies found that GLP-1 and other incretin hormones, such as GIP or GLP-2, could have positive effects on bone through antiresorptive and anabolic properties, suggesting beneficial effects of antidiabetic drugs like GLP-1RAs or DPP-4 inhibitors on bone metabolism. These appear to involve Wnt/betacatenin pathway, Osteoprotegerin (OPG)/RANKL (Receptor activator of nuclear factor kappa-B ligand) ratio and sclerostin levels (Fig. 1) (Ceccarelli et al. 2013). Osteoblasts and osteoclasts express receptors for both GIP and GLP incretins (Zofkova 2015).

In a murine model, a genetic disruption of GLP-1 receptor signalling resulted in cortical osteopenia and an increase in bone fragility as a result of greater bone resorption by osteoclasts, which was associated with a reduction in thyroid calcitonin expression (Yamada et al. 2008). A GLP-1 agonist, exendin-4 has been shown to decrease the urinary deoxypyridinoline (DPD)/creatinine ratio and serum C-terminal cross-linked telopeptides of type I collagen (CTX-I) and increase serum alkaline phosphatase (ALP), osteocalcin, and $\mathrm{N}$-terminal propeptide of type 1 procollagen (P1NP) levels in ovariectomized Sprague-Dawley rats (Ma et al. 2013, Meng et al. 2016).

A relationship between incretin hormones and bone has been investigated also in humans. Evidence of incretin effects in humans showed a decrease in nocturnal bone resorption after administration of GLP-2. Results reported the absence of any toxic effect of GLP-2 treatment and more interestingly, a dose dependent increase in BMD. Injection of GLP-2 determined an immediate and sustained decrease in bone resorption markers, while levels of bone formation markers, were

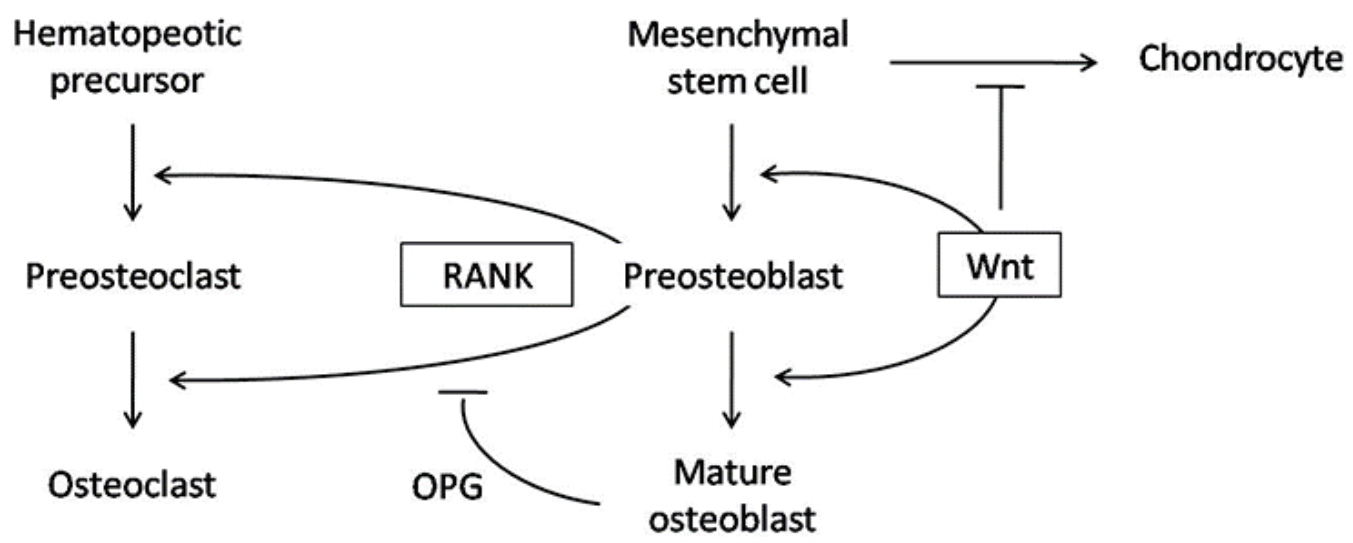

Fig. 1. Role of the Wnt-signalling pathway in regulation of osteoblast (bone-forming cell) and osteoclast (bone-resorbing cell) differentiation. Wnt-signaling diverts the mesenchymal stem cells down the pathway of osteoblast differentiation. The precursors of the mature osteoblast enhance bone resorption by boosting RANKL-induced osteoclastogenesis. Activation of the Wnt-signaling pathway in the mature osteoblast upregulates osteoprotegerin (OPG), which blocks RANKL-induced osteoclastogenesis, resulting in inhibition of bone resorption. 
not affected, thus providing evidence of a direct action of incretin hormones in regulation of bone metabolism (Henriksen et al. 2009, Holst et al. 2016).

In a clinical trial, T2DM patients were randomized to receive GLP-1RAs exenatide or insulin glargine, added to their metformin-based therapy. After 44 weeks of treatment, the different drug regimen did not affect BMD. These findings suggest that, in T2DM patients, long-term injection of exenatide will not lead to an increase in fracture risk (Bunck et al. 2011).

Recently was reported that the use of exenatide and liraglutide did not modify the fracture risk in T2DM as compared to placebo or other anti-hyperglycemic medications (glimepiride, sitagliptin, and insulin) in a meta-analysis of 7 RCTs (Mabilleau et al. 2013). Another metaanalysis of 16 RCTs variable duration (12 to 104 weeks) exploring the association between fractures and GLP-1RAs in general and liraglutide or exenatide in particular. Overall, the effect of GLP-1RAs on fracture risk seems to be neutral ( $\mathrm{Su}$ et al. 2015). A case-control study using Danish National Health Service concluded that the use of GLP-1RAs was not associated with fracture risk as compared to the use of other anti-hyperglycemic drugs. Additionally, current GLP-1RAs use, stratified by cumulative or average daily dose, is not associated with fracture risk (Driessen et al. 2015).

In a meta-analysis which included 28 trials showed a $40 \%$ reduced risk of fractures in patients treated by DPP-4 inhibitors compared with placebo or other anti-hyperglycemic treatments. Neutral role of DPP-4 inhibitors on bone metabolism was demonstrated by treatment with vildagliptin in drug naïve T2DM patients for 1 year. Circulating levels of markers of bone resorption and calcium homeostasis were unaffected compared with baseline and to placebo (Monami et al. 2011).

Recently the fracture incidence among participants in the Trial Evaluating Cardiovascular Outcomes with Sitagliptin (TECOS) was examined. During 43,222 person-years follow-up 375 patients (2.6\%; 8.7 per 1000 person-years) had a fracture. In conclusion fractures were common among people with DM in the TECOS study, but were not related to sitagliptin therapy. Insulin and metformin treatment were associated with higher and lower fracture risks, respectively (Josse et al. 2017).

Specifically, data so far available both from experimental animal models and man, indicate that the beneficial "extraglycemic" effects of incretin-based drugs include the effects on bone metabolism, either directly on bone cells or indirectly (e.g., via thyroid $\mathrm{C}$ cells and calcitonin), appear to favor bone formation and to inhibit bone resorption, thus improving bone strength (Fig. 2).

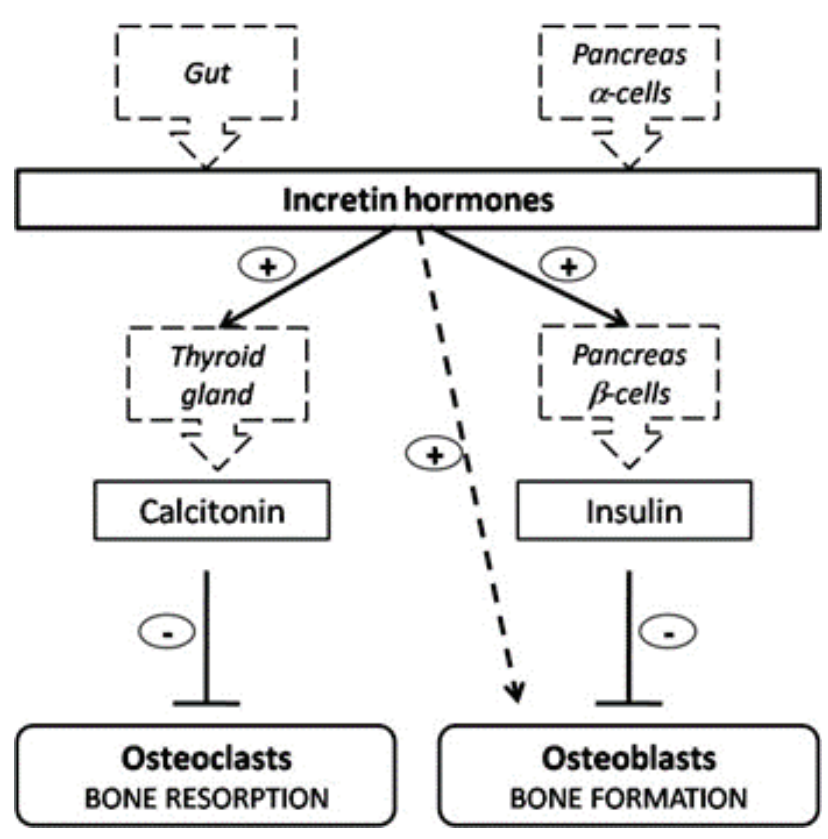

Fig. 2. Effects of incretin hormones on bone metabolism. Incretin hormones are secreted by intestinal L-cells and, in minor amounts, by pancreatic $\alpha$-cells. Incretin hormones can stimulate osteoblastogenesis indirectly via increased insulin secretion as well as through a direct action on osteoblasts. Moreover, incretin hormones can inhibit osteoclastogenesis by stimulating calcitonin production.

\section{Selective inhibitor of sodium-glucose cotransporter-2}

Given the renal tubular mechanism of action of the sodium-glucose cotransporter-2 (SGLT-2) inhibitor class, these drugs may potentially alter calcium and phosphate homeostasis and bone mineral density (BMD).

Dapagliflozin, a selective sodium-glucose cotransporter-2 (SGLT-2) inhibitor, reduces hyperglycaemia in patients with T2D by increasing urinary glucose excretion. Preliminary clinical data showed no changes in serum calcium or vitamin $\mathrm{D}$ but small increases in serum magnesium, phosphate and parathyroid hormone with dapagliflozin treatment compared with placebo (List et al. 2009, Nauck et al. 2011). Furthermore, dapagliflozin-induced urinary caloric loss produces weight loss, which may also potentially reduce BMD. Dapagliflozin had no effect on markers of bone formation and resorption or BMD after 50 weeks of treatment in 
both male and post-menopausal female patients whose T2DM was inadequately controlled using metformin (Ljunggren et al. 2012).

These data, however, are in contrast with recently published skeletal safety data with increased fracture incidence associated with the use of dapagliflozin and canagliflozin (Kohan et al. 2014, Watts et al. 2016). In a double-blind, placebo-controlled study of adults with T2DM and moderate renal impairment, substantial increases in fracture numbers were noted in the dapagliflozin groups with a suggestion of dose dependency (Kohan et al. 2014). All 13 (7.7\%) fractures occurred after trauma and were mostly of low impact. Similarly, the incidence of fractures was higher with canagliflozin $(2.7 \%)$ vs non-canagliflozin $(1.9 \%)$ in the overall population of patients from 9 placebo- and activecontrolled, randomized, double-blind, phase 3 studies with scheduled exposures to canagliflozin 100 or $300 \mathrm{mg}$ for 1 year or longer, with the same incidence in the canagliflozin 100 and $300 \mathrm{mg}$ groups (Watts et al. 2016).

In November 2015, the US Food and Drug Administration (FDA) issued a warning for canagliflozin regarding the risk for bone fractures with new information about decreased bone mineral density. The FDA recommends health care professionals to consider factors that affect the risk of fracture prior to prescribing canagliflozin for patients.

There are plausible pathophysiological mechanisms with potential to mediate detrimental skeletal effects of SGLT-2 inhibitors. Use of these drugs is consistently associated with weight loss (Tahrani et al. 2013). This might contribute to bone loss, in part, due to the direct effect of reduced soft-tissue mass on bone through reduced mechanical loading (Martin 2007). Additionally, decreased fat tissue might lead to reductions in aromatase activity, which lowers the production of estradiol and consequently increases bone turnover (Gonnelli et al. 2011, Liu et al. 2014). The decrease in estradiol in women with canagliflozin is consistent with this hypothesis (Bilezikian et al. 2016). SGLT-2 inhibition may reduce sodium transport in the proximal tubule epithelial cells, leading to increased phosphate flux through the sodium-phosphate cotransporter and to increased serum phosphate (Taylor et al. 2015). This effect might stimulate the secretion of PTH whose sustained increase enhances bone resorption and increases the risk of fractures.

Other paper reported no significant changes from baseline in bone turnover markers and BMD after dapagliflozin treatment in patients with normal to mild renal impairment (Ljunggren et al. 2012). On the other hand, canagliflozin has been reported to increase bone turnover (Bilezikian et al. 2016, Rosenstock et al. 2012).

In a pooled analysis of $>12,000$ patients or compared with glimepiride in a 4-year head-to-head study empagliflozin also did not increase the risk of bone fracture compared with placebo. Bone fracture AEs were reported only in 2-4\% of all patients (Kohler et al. 2018).

\section{Insulin as a treatment}

The distinct reduction of peak bone mass in some patients with T1DM has led to the hypothesis that insulin has osteoanabolic effects although it is unclear whether the effects on BMD are caused by poor glycemic control or other diabetic complications (Hofbauer et al. 2007, Klein 2014, Moayeri et al. 2017).

In a review, it was suggested that insulin exerts a potent bone anabolic effect on osteoblasts through receptor-mediated mechanisms (Thrailkill et al. 2005). Lack of insulin led to low bone mass in an uncontrolled study of 57 patients with T1DM and a mean age of 35 years, who were evaluated before intensive insulin therapy and 7 years later. Treatment was associated with substantial improvement of bone mass and bone turnover biomarkers (Campos Pastor et al. 2000).

Insulin has direct effects on bone metabolism in humans and changes in the circulating levels of bone markers can be seen within a few hours after administration of insulin (Ivaska et al. 2015).

Hyperinsulinemia in patients with T2DM might contribute to the high $\mathrm{BMD}$, although insulin resistance in bone cells may occur. Differences in skeletal effects between patients with T1DM and those with T2DM are not, therefore, fully explained by the "insulinopenia" hypothesis. In addition to insulin, pancreatic beta-cells produce other osteotropic factors, such as islet amyloid polypeptide (IAPP, also known as amylin) and preptin, both of which are members of the calcitonin-gene-related peptide family. Production of these peptides is abolished in patients with T1DM. IAPP, a 37-amino-acid peptide, is secreted with insulin (Naot et al. 2008).

A study on 243 patients with T2DM found that there was no difference in BMD between women with T2DM treated with diet, oral antidiabetics or insulin therapy, but BMD was lower in men with T2DM undergoing insulin treatment (LSMEAN \pm SE; FN-BMD $0.86 \pm 0.02 \mathrm{~g} / \mathrm{cm}^{2}$, LS-BMD $1.035 \pm 0.02 \mathrm{~g} / \mathrm{cm}^{2}$ ) compared 
with those treated with other therapies (FN-BMD $0.91 \pm 0.02 \mathrm{~g} / \mathrm{cm}^{2} ;$ LS-BMD $\left.1.13 \pm 0.02 \mathrm{~g} / \mathrm{cm}^{2}\right)(\mathrm{p}=0.02$; $\mathrm{p}=0.004)$ (Leidig-Bruckner et al. 2014). Also some other studies demonstrated that insulin therapy was associated with a higher risk of vertebral fractures (Kanazawa et al. 2009). This may be due to the fact that, for example, T2DM patients on insulin therapy are likely to have longer disease duration and/or complications, or a higher risk of hypoglycemic events. According to the studies of osteoporotic fractures, insulin treated older women with DM had more than double the risk of foot fractures, because of falling and diabetic complication like neuropathy, compared with non-diabetics and noninsulin DM users (Schwartz et al. 2002). Similarly studies among the Rochester cohort showed that insulin slightly but significantly increases fracture rate.

Insulin therapy is associated with an increased frequency of severe hypoglycemic events and therefore an increased risk of falling which can contribute to fracture risk (Ferrari 2017, Chandran 2017).

Interestingly, insulin-treated women with DM have almost a doubled fall incidence (OR 2.78 vs. 1.68), which in part explains the increased fracture rate in the lower extremities (Schwartz et al. 2002). Older adults with T2DM are more likely to fall, but little is known about risk factors for falls in this population. A study determined whether diabetes-related complications or treatments are associated with risk of falls in older adults with DM (Schwartz et al. 2008). In older adults with DM falls may be prevented by reducing diabetes-related complications. Achieving lower A1C levels with oral hypoglycemic medications was not associated with more falls, but, among those using insulin, $\mathrm{A} 1 \mathrm{C} \leq 6 \%$ increased risk of falls. This was also the first study of falls to report an interaction between insulin use and A1C levels. Some, but not all, previous studies have reported increased risk of falls among those using insulin (Quandt et al. 2006). Another study group reported increased risk of falls with poor glycemic control (A1C>7\%) (Tilling et al. 2006).

\section{Recommendations for the diagnosis and therapy for osteoporosis in patients with DM}

Markers of bone resorption and formation seem to be lower in patients with DM (Starup-Linde et al. 2016). This can lead to the concerns that antiresorptive therapy may not be effective for fracture prevention in diabetic patient (Zofkova and Blahos 2017). Evidence about the effect of antiosteoporotic treatment remains limited (Table 2). Generally, the trials and also the clinical practice indicate that the antifracture efficacy is similar in patient with and without DM.

Table 2. Established osteoporosis therapies in patient with diabetes - drugs with evidence of reducing the risk of fractures when used with adequate calcium and vitamin D supplementation

\begin{tabular}{|c|c|c|c|c|}
\hline Drug & Dose and interval & $\begin{array}{c}\text { Route of } \\
\text { administration }\end{array}$ & $\begin{array}{c}\text { Anti-Fracture } \\
\text { efficacy }\end{array}$ & Efficacy in diabetes \\
\hline Alendronate & 70 mg weekly & Oral & $\begin{array}{c}\text { Hip-fractures } \\
\text { Vertebral fractures }\end{array}$ & Clinical Studies \\
\hline Risedronate & $\begin{array}{c}35 \mathrm{mg} \text { weekly } \\
150 \mathrm{mg} \text { monthly }\end{array}$ & Oral & $\begin{array}{c}\text { Hip-fractures } \\
\text { Vertebral fractures }\end{array}$ & Daily Practice \\
\hline Ibandronate & $\begin{array}{c}150 \mathrm{mg} \text { monthly } \\
3 \mathrm{mg} \text { every } 3 \text { months }\end{array}$ & Oral & Vertebral fractures & Daily Practice \\
\hline Zolendronic acid & $5 \mathrm{mg}$ yearly & Intravenous & $\begin{array}{c}\text { Hip-fractures } \\
\text { Vertebral fractures }\end{array}$ & Daily Practice \\
\hline Raloxifene & 60 mg daily & Oral & Vertebral fractures & Clinical Studies \\
\hline Stroncium ranelate & 2 g daily & Oral & $\begin{array}{c}\text { Hip-fractures } \\
\text { Vertebral fractures }\end{array}$ & Daily Practice \\
\hline Denosumab & 60 mg every 6 month & Subcutaneous & $\begin{array}{c}\text { Hip-fractures } \\
\text { Vertebral fractures }\end{array}$ & Daily Practice \\
\hline$T P T D\left(P T H_{1-34}\right)$ & $20 \mu \mathrm{g}$ daily & Subcutaneous & Vertebral fractures & Clinical Studies \\
\hline
\end{tabular}

Clinical studies $=$ mostly retrospective analyses of subgroups with diabetes, few prospective clinical trials

Clinical practice $=$ results from daily practice of treating patient with osteoporosis - the drug is in patient with diabetes effective, without adverse events 
FIT trial (Fracture Intervention Trial) found that alendronate increases BMD in women with DM similar to its effect in women without DM (Keegan et al. 2004).

Subgroup analyses of the RUTH trial (Raloxifene Use for the Heart Trial) found reduced risk of vertebral fractures in both women with and also without DM treated by raloxifene (Ensrud et al. 2008).

Direct Analysis of Nonvertebral Fracture in the Community Experience (DANCE) study with 4042 patients (291 with T2DM, 3751 without DM) showed that during teriparatide treatment, reduction in nonvertebral fracture incidence, increase in BMD, and decrease in back pain were similar in T2DM and non-diabetic patients (Schwartz et al. 2016). The effect of teriparatide in diabetic patients was confirmed also in next study (Real-World Effectiveness of Teriparatide), for patients with and without DM fracture rates decreased significantly in the $>6$-month period for all fracture types. The reduction in clinical fracture rate was greater for the diabetic $(-77 \%)$ versus the nondiabetic subgroup $(-48 \%$, interaction $\mathrm{p}=0.046)$; however, reductions in fracture rates in both subgroups were statistically significant (Langdahl et al. 2018). It can be concluded that teriparatide treatment had a significant effect for all fracture types and no impact of diabetes on overall fracture rate.

According the mechanism of action, denosumab should be also effective in treatment of osteoporosis in diabetics. It was shown that denosumab did not affect fasting plasma glucose (FPG) in postmenopausal osteoporotic women with prediabetes or diabetes mellitus. There was evidence of modest FPG lowering with denosumab in those with DM who were not on OADs. It remains to be determined whether blockade of RANKL has a clinically important effect on glucose metabolism (Napoli et al. 2018).

In conclusion, DM does not seem to affect the fracture-preventive potential of bisphosphonates or raloxifene (Vestergaard et al. 2011). Post hoc analyses of the DANCE (The Direct Assessment of Nonvertebral Fractures in Community Experience) observational study compared T2D patients and patients without DM to assess the effect of teriparatide, an osteoanabolic therapy. During teriparatide treatment, reduction in nonvertebral fracture incidence, increase in BMD, and decrease in back pain were similar in T2D and non-diabetic patients (Schwartz et al. 2016). The data about the effect of denosumab and strontium ranelate are still missing. An interesting finding is that denosumab, an antiRANKL antibody, enhanced human $\beta$-cell replication in humanized mice. The researchers highlight the potential for repurposing an osteoporosis drug to treat DM (Kondegowda et al. 2015).

\section{Algorithm for management of osteoporosis in patient with T2DM}

All above mentioned data were given in an algorithm for management of osteoporosis in women and men with T2DM (Fig. 3). First step of the algorithm is how to evaluate osteoporosis risk in a patient with T2DM. According the European guidance, it is recommended that postmenopausal women with a prior fragility fracture should be treated without further assessment, although BMD measurement and incorporation into the FRAX calculation is sometimes appropriate, particularly in younger postmenopausal women. In women without a previous fragility fracture, the management strategy should be based on assessment of the ten-year probability of a major osteoporotic fracture (clinical spine, hip, forearm or humerus) (Kanis et al. 2019). Fracture-risk evaulation should be performed in all patient age $>50$ years and/or with diabetes specific risk factors for fractures $=$ diabetes duration $>5$ years; diabetes medication insulin, TZDs, possibly SGLT2 inhibitors; HbAlc $>7 \%$; microvascular complications peripheral and autonomic neuropathy, retinopathy, nephropathy (Ferrari et al. 2018).

However, T-score BMDmeasured by DXAmay underestimate fracture risk in patients with diabetes. Thus, a BMD intervention threshold at T-score -2.0 SD at spine or hip could be considered appropriate (Ferrari et al. 2018).

The diagnostic algorithm is based on recent guidelines published by IOF working group (Ferrari et al. 2018).

All patients should have an adequate intake of vitamin $\mathrm{D}$ and calcium, not only to improve bone health, but also to improve the metabolic compensation. If we have a patient with osteoporosis and/or osteoporotic fracture, we should initiate the antifracture treatment with effective antiporotic medication. In general management we have to look also on the bone-effects of antidiabetic drugs. 


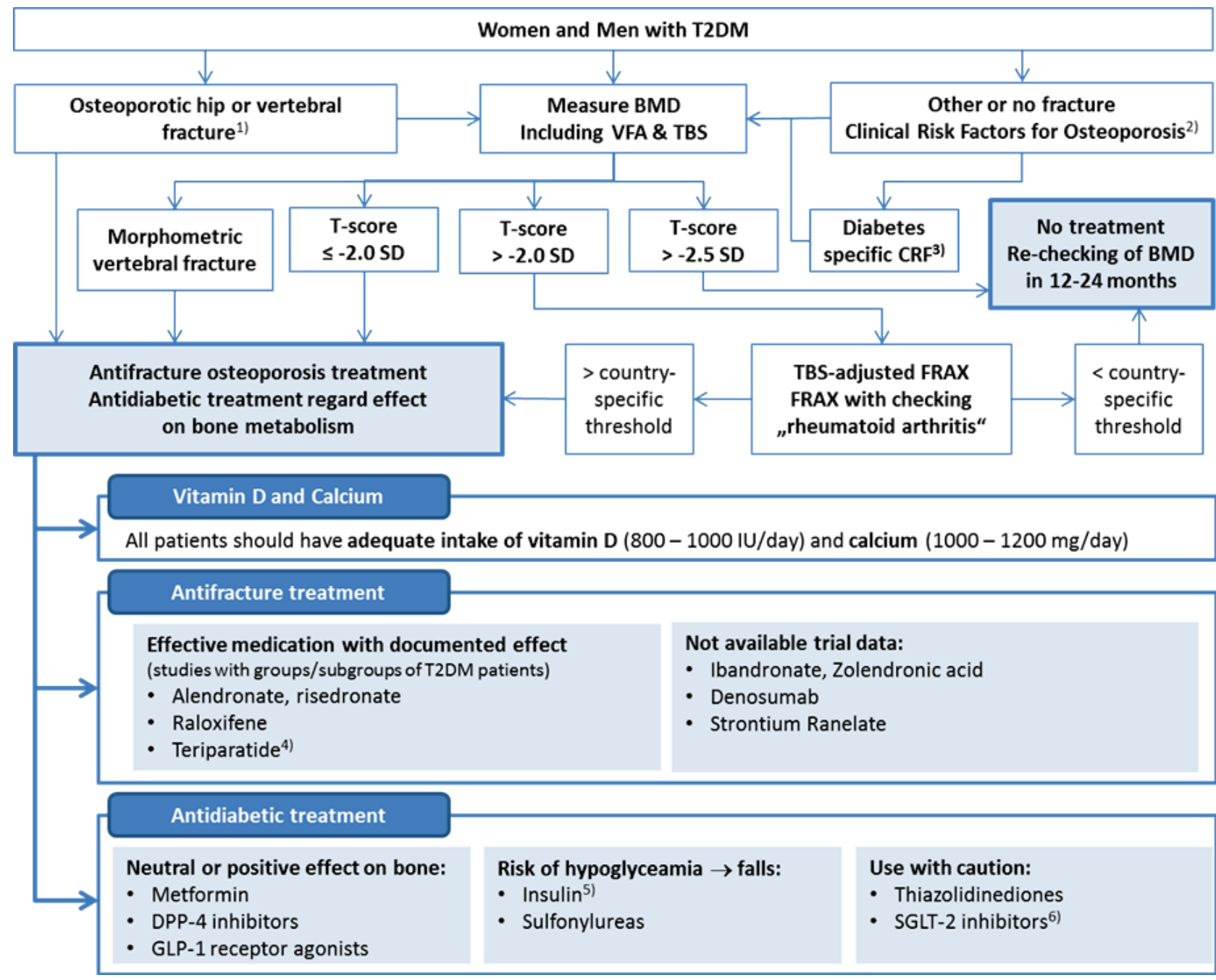

Fig. 3. Recommended algorithm for management in women and men with T2DM. Explanatory Notes: ${ }^{1)}$ Osteoporotic fractures - fragility fractures, low-trauma fractures - typical are hip, spine, distal radius. Diabetic patients are also at increased risk of fracture in ankle, humerus and pelvis fracture. ${ }^{2}$ Clinical Risk Factors for osteoporosis: women age > 50 years; men age > 65 years; prior fracture; family history of hip-fracture; alcohol; smoking; glucocorticosteroids use; hypogonadism, high fall propensity, insulin therapy. ${ }^{3)}$ In all patients age $>50$ years and/or with diabetes specific risk factors for fractures = diabetes duration > 5 years; diabetes medication insulin, TZDs, possibly SGLT2 inhibitors; HbA1c>7\%; microvascular complications - peripheral and autonomic neuropathy, retinopathy, nephropathy. ${ }^{4)}$ TPTD indication according the country-specifics rules for osteoanabolic treatment. ${ }^{5}$ When insulin is indicated/necessary for the (initial) treatment of diabetes it can be used as first line therapy (osteology view: benefit is higher than risk). Insulin treated patients have higher risk of falls, episodes of hypoglycemia, have more serious form of diabetes with complications and other comorbidities $\rightarrow$ this factors can lead to higher risk of osteoporotic fractures. ${ }^{6}$ Empagliflozin and dapagliflozin are seen to be neutral on bone. Abbreviations: CRF = clinical risk factors; DPP-4 = dipeptidyl peptidase 4; GLP-1 = glucagon like peptide 1 ; SGLT-2 = sodiumglucose cotransporter 2

\section{Conclusion}

Achieving adequate glycemic control in patients with DM is especially important as there are data to suggest that the microvascular complications of DM, such as retinopathy, neuropathy, and macro-vasculopathy which arise from insufficient glycemic control, can lead to falls and subsequent fractures. Several antidiabetic drugs have been demonstrated to influence bone metabolism. From a bone perspective, metformin and DPP-4 inhibitors are safer than TZDs and sulphonylureas, or SGLT-2 inhibitors. Conversely, current treatment with insulin increases the risk of fractures, at the same time exposure to this agent in the longer term does not appear to affect bone frailty. If no contraindications exist, intensive insulin therapy is the standard treatment for DM and seems to be associated with improved skeletal health. The risk of hypoglycemic episodes, which constitute an adverse effect of intensive insulin therapy, should be minimized by comprehensive patient education, frequent self-monitoring of glucose levels and titration of the insulin dose. 
The effect on bone metabolism and fracture risk deserves to be included into the evaluation of risk-benefit ratio of anti-hyperglycemic drugs. Positive and negative expectations for the newer drugs still need to be confirmed. Future research could specifically identify patients who are most susceptible to development of drug-induced bone fractures.

\section{Conflict of Interest}

There is no conflict of interest.

\section{References}

BERBEROGLU Z, YAZICI AC, DEMIRAG NG: Effects of rosiglitazone on bone mineral density and remodelling parameters in postmenopausal diabetic women: a 2-year follow-up study. Clin Endocrinol 73: 305-312, 2010.

BILEZIKIAN JP, WATTS NB, USISKIN K, POLIDORI D, FUNG A, SULLIVAN D, ROSENTHAL N: Evaluation of bone mineral density and bone biomarkers in patients with type 2 diabetes treated with canagliflozin. $J$ Clin Endocrinol Metab 101: 44-51, 2016.

BUNCK MC, ELIASSON B, CORNÉR A, HEINE RJ, SHAGINIAN RM, TASKINEN MR, YKI-JÄRVINEN H, SMITH U, AND DIAMANT M: Exenatide treatment did not affect bone mineral density despite body weight reduction in patients with type 2 diabetes. Diabetes Obesity Metab 13: 374-377, 2011.

CAMPOS PASTOR MM, LOPEZ-IBARRA PJ, ESCOBAR-JIMENEZ F, SERRANO PARDO MD, GARCIACERVIGON AG: Intensive insulin therapy and bone mineral density in type 1 diabetes mellitus: a prospective study. Osteoporos Int 11: 455-459, 2000.

CECCARELli E, GUARINO E, MERLOTTI D, PATTI A, GENNARI L, NUTI R, DOTTA F: Beyond glycemic control in diabetes mellitus: effects of incretin-based therapies on bone metabolism. Front Endocrinol 4: 1-12, 2013.

CIRMANOVA V, ZOFKOVA I, KASALICKY P, LANSKA V, BAYER M, STARKA L, KANCEVA R: Hormonal and bone parameters in pubertal girls. Physiol Res 66 (Suppl. 3): S419-S424, 2017.

CORTIZO AM, SEDLINSKY C, MCCARTHY AD, BLANCO A, SCHURMAN L: Osteogenic actions of the antidiabetic drug metformin on osteoblasts in culture. Eur J Pharmacol 536: 38-46, 2006.

DRIESSEN JH, VAN ONZENOORT HA, STARUP-LINDE J, HENRY R, BURDEN AM, NEEF C, VAN DEN BERGH JP, VESTERGAARD P, DE VRIES F: Use of glucagon-like-peptide 1 receptor agonists and risk of fracture as compared to use of other anti-hyperglycemic drugs. Calcif Tissue Int 97: 506-515, 2015.

ENSRUD KE, STOCK JL, BARRETT-CONNOR E, GRADY D, MOSCA L, KHAW K-T, ZHAO Q, AGNUSDEI D, CAULEY JA: Effects of raloxifene on fracture risk in postmenopausal women: the raloxifene use for the heart trial. J Bone Mineral Res 23: 112-120, 2008.

FERRARI S: Diabetes and bone. Calcif Tissue Int 100: 107-108, 2017.

FERRARI SL, ABRAHAMSEN B, NAPOLI N, AKESSON K, CHANDRAN M, EASTELL R, EL-HAJJ FULEIHAN G, JOSSE R, KENDLER DL, KRAENZLIN M, SUZUKI A, PIERROZ DD, SCHWARTZ AV, LESLIE WD: Diagnosis and management of bone fragility in diabetes: an emerging challenge. Osteoporos Int 29: 2585-2596, 2018.

FERRON M, WEI J, YOSHIZAWA T, FATTORE A, DEPINHO R, TETI A, DUCY P, KARSENTY G: Insulin signaling in osteoblasts integrates bone remodeling and energy metabolism. Cell 142: 296-308, 2010.

FOWLKES JL, BUNN R C, THRAILKILL KM: Contributions of the insulin/insulin-like growth factor-1 axis to diabetic osteopathy. J Diabetes Metab 1: S1-003, 2011.

FUKUNAGA T, ZOU W, ROHATGI N, COLCA JR, TEITELBAUM SL: An Insulin-Sensitizing Thiazolidinedione, Which Minimally Activates PPAR $\gamma$, Does Not Cause Bone Loss. J Bone Mineral Res 30: 481-488, 2015.

GILBERT MP, PRATLEY RE: The Impact of Diabetes and Diabetes Medications on Bone Health. Endocrine Rev 36: 194-213, 2015.

GONNELLI S, CAFFARELLI C, TANZILLI L, MERLOTTI D, GENNARI L, ROSSI S, LUCANI B, CAMPAGNA MS, FRANCI B, NUTI R: The association of body composition and sex hormones with quantitative ultrasound parameters at the calcaneus and phalanxes in elderly women. Calcif Tissue Int 89: 456-463, 2011.

GU Q, GU Y, YANG H, SHI Q: Metformin enhances osteogenesis and suppresses adipogenesis of human chorionic villous mesenchymal stem cells. Tohoku J Exp Med 241: 13-19, 2017. 
HAYAKAWA N, SUZUKI A: Diabetes mellitus and osteoporosis. Effect of antidiabetic medicine on osteoporotic fracture. Clin Calcium 22: 1383-1390, 2012.

HEGAZY SK: Evaluation of the anti-osteoporotic effects of metformin and sitagliptin in postmenopausal diabetic women. J Bone Mineral Metab 33: 207-212, 2015.

HENRIKSEN DB, ALEXANDERSEN P, HARTMANN B, ADRIAN CL, BYRJALSEN I, BONE HG, HOLST JJ, CHRISTIANSEN C: Four-month treatment with GLP-2 significantly increases hip BMD: a randomized, placebo-controlled, dose-ranging study in postmenopausal women with low BMD. Bone 45: 833-842, 2009.

HOFBAUER LC, BRUECK CC, SINGH SK, DOBNIG H: Osteoporosis in patients with diabetes mellitus. $J$ Bone Mineral Res 22: 1317-1328, 2007.

HOLST JJ, WINDELØV JA, BOER GA, PEDERSEN J, SVENDSEN B, CHRISTENSEN M, TOREKOV S, ASMAR M, HARTMANN B, NISSEN A: Searching for the physiological role of glucose-dependent insulinotropic polypeptide. J Diabetes Investig 7: 8-12, 2016.

HOUGH FS, PIERROZ DD, COOPER C, FERRARI SL, BONE TIC, GROUP DW: Mechanisms and evaluation of bone fragility in type 1 diabetes mellitus. Eur J Endocrinol 174: R127-R138, 2016.

CHANDRAN M: Diabetes drug effects on the skeleton. Calcif Tissue Int 100: 133-149, 2017.

IVASKA KK, HELIÖVAARA KM, EBELING P, BUCCI M, HUOVINEN V, KALERVO VÄÄNÄNEN H, NUUTILA P, A KOISTINEN H: The effects of acute hyperinsulinemia on bone metabolism. Endocr Connect 4: 155-162, 2015.

JACKULIAK P, PAYER J: Osteoporosis, fractures, and diabetes. Int J Endocrinol 2014: 10, 2014.

JOSSE RG, MAJUMDAR SR, ZHENG Y, ADLER A, BETHEL MA, BUSE JB, GREEN JB, KAUFMAN KD, RODBARD HW, TANKOVA T, WESTERHOUT CM, PETERSON ED, HOLMAN RR, ARMSTRONG PW, ON BEHALF OF THE TSG: Sitagliptin and risk of fractures in type 2 diabetes: results from the tecos trial. Diabetes Obes Metab 19: 78-86, 2017.

KAHN SE, ZINMAN B, LACHIN JM, HAFFNER SM, HERMAN WH, HOLMAN RR, KRAVITZ BG, YU D, HEISE MA, AFTRING RP, VIBERTI G: Rosiglitazone-associated fractures in type 2 diabetes. An analysis from A Diabetes Outcome Progression Trial (ADOPT). Diabetes Care 31: 845-851, 2008.

KANAZAWA I, YAMAGUCHI T, YAMAMOTO M, YAMAUCHI M, YANO S, SUGIMOTO T: Relationships between serum adiponectin levels versus bone mineral density, bone metabolic markers, and vertebral fractures in type 2 diabetes mellitus. Eur J Endocrinol 160: 265-273, 2009.

KANIS JA, COOPER C, RIZZOLI R, REGINSTER JY: European guidance for the diagnosis and management of osteoporosis in postmenopausal women. Osteoporos Int 30: 3-44, 2019.

KEEGAN THM, SCHWARTZ AV, BAUER DC, SELLMEYER DE, KELSEY JL: Effect of alendronate on bone mineral density and biochemical markers of bone turnover in type 2 diabetic women; The fracture intervention trial Diabetes Care 27: 1547-1553, 2004.

KLEIN GL: Insulin and bone: Recent developments. World J Diabetes 5: 14-16, 2014.

KOHAN DE, FIORETTO P, TANG W, LIST JF: Long-term study of patients with type 2 diabetes and moderate renal impairment shows that dapagliflozin reduces weight and blood pressure but does not improve glycemic control. Kidney Int 85: 962-971, 2014.

KOHLER S, KASPERS S, SALSALI A, ZELLER C, WOERLE HJ: Analysis of fractures in patients with type 2 diabetes treated with empagliflozin in pooled data from placebo-controlled trials and a head-to-head study versus glimepiride. Diabetes Care 41: 1809-1816, 2018.

KONDEGOWDA NAGESHA G, FENUTRIA R, POLLACK ILANA R, ORTHOFER M, GARCIA-OCAÑA A, PENNINGER JOSEF M, VASAVADA RUPANGI C: Osteoprotegerin and denosumab stimulate human beta cell proliferation through inhibition of the receptor activator of NF-KB ligand pathway. Cell Metab 22: 77-85, 2015.

KURRA S, SIRIS E: Diabetes and bone health: the relationship between diabetes and osteoporosis-associated fractures. Diabetes/Metab Res Rev 27: 430-435, 2011.

LANGDAHL BL, SILVERMAN S, FUJIWARA S, SAAG K, NAPOLI N, SOEN S, ENOMOTO H, MELBY TE, DISCH DP, MARIN F, KREGE JH: Real-world effectiveness of teriparatide on fracture reduction in patients with osteoporosis and comorbidities or risk factors for fractures: Integrated analysis of 4 prospective observational studies. Bone 116: 58-66, 2018. 
LAPANE KL, YANG S, BROWN MJ, JAWAHAR R, PAGLIASOTTI C, RAJPATHAK S: Sulfonylureas and risk of falls and fractures: a systematic review. Drugs Aging 30: 527-547, 2013.

LECKA-CZERNIK B: Bone loss in diabetes: use of antidiabetic thiazolidinediones and secondary osteoporosis. Curr Osteoporos Rep 8: 178-184, 2010.

LECKA-CZERNIK B: Safety of anti-diabetic therapies on bone. Clin Rev Bone Miner Metab 11: 49-58, 2013.

LEIDIG-BRUCKNER G, GROBHOLZ S, BRUCKNER T, SCHEIDT-NAVE C, NAWROTH P, SCHNEIDER JG: Prevalence and determinants of osteoporosis in patients with type 1 and type 2 diabetes mellitus. BMC Endocr Disord 14: 33, 2014.

LIST JF, WOO V, MORALES E, TANG W, FIEDOREK FT: Sodium-glucose cotransport inhibition with dapagliflozin in type 2 diabetes. Diabetes Care 32: 650-657, 2009.

LIU M, GOSS PE, INGLE JN, KUBO M, FURUKAWA Y, BATZLER A, JENKINS GD, CARLSON EE, NAKAMURA Y, SCHAID DJ, CHAPMAN J-AW, SHEPHERD LE, ELLIS MJ, KHOSLA S, WANG L, WEINSHILBOUM RM: Aromatase inhibitor-associated bone fractures: a case-cohort gwas and functional genomics. Mol Endocrinol 28: 1740-1751, 2014.

LJUNGGREN Ö, BOLINDER J, JOHANSSON L, WILDING J, LANGKILDE AM, SJÖSTRÖM CD, SUGG J, PARIKH S: Dapagliflozin has no effect on markers of bone formation and resorption or bone mineral density in patients with inadequately controlled type 2 diabetes mellitus on metformin. Diabetes Obes Metab 14: 990-999, 2012.

LOKE YK, SINGH S, FURBERG CD: Long-term use of thiazolidinediones and fractures in type 2 diabetes: a metaanalysis. Can Med Assoc J 180: 32-39, 2009.

MA X, MENG J, JIA M, BI L, ZHOU Y, WANG Y, HU J, HE G, LUO X: Exendin-4, a glucagon-like peptide-1 receptor agonist, prevents osteopenia by promoting bone formation and suppressing bone resorption in aged ovariectomized rats. J Bone Mineral Res 28: 1641-1652, 2013.

MABILLEAU G, MIECZKOWSKA A, IRWIN N, FLATT PR, CHAPPARD D: Optimal bone mechanical and material properties require a functional glucagon-like peptide-1 receptor. $J$ Endocrinol 219: 59-68, 2013.

MAJUMDAR SR, LESLIE WD, LIX LM, MORIN SN, JOHANSSON H, ODEN A, MCCLOSKEY EV, KANIS JA: Longer duration of diabetes strongly impacts fracture risk assessment: The Manitoba BMD Cohort. J Clin Endocrinol Metab 101: 4489-4496, 2016.

MARCHETTI P, LUPI R, BUGLIANI M, KIRKPATRICK CL, SEBASTIANI G, GRIECO FA, DEL GUERRA S, D'ALEO V, PIRO S, MARSELLI L, BOGGI U, FILIPPONI F, TINTI L, SALVINI L, WOLLHEIM CB, PURRELLO F, DOTTA F: A local glucagon-like peptide 1 (GLP-1) system in human pancreatic islets. Diabetologia 55: 3262-3272, 2012.

MARTIN RB: The importance of mechanical loading in bone biology and medicine. J Musculoskelet Neuronal Interact 7: 48-53, 2007.

MAZZIOTTI G, CANALIS E, GIUSTINA A: Drug-induced osteoporosis: mechanisms and clinical implications. The Am J Med 123: 877-884, 2010.

MCCARTHY AD, CORTIZO AM, SEDLINSKY C: Metformin revisited: Does this regulator of AMP-activated protein kinase secondarily affect bone metabolism and prevent diabetic osteopathy. World J Diabetes 7: 122-133, 2016.

MEHTA S: Comparative safety of oral antidiabetic therapy on risk of fracture in patients with diabetes. In: American Diabetes Association 2014 Scientific Sessions; 2014, p. 165-OR.

MELTON LJ, LEIBSON CL, ACHENBACH SJ, THERNEAU TM, KHOSLA S: Fracture risk in type 2 diabetes: update of a population-based study. J Bone Miner Res 23: 1334-1342, 2008.

MENG J, MA X, WANG N, JIA M, BI L, WANG Y, LI M, ZHANG H, XUE X, HOU Z, ZHOU Y, YU Z, HE G, LUO X: Activation of GLP-1 receptor promotes bone marrow stromal cell osteogenic differentiation through B-catenin. Stem Cell Rep 6: 579-591, 2016.

MIECZKOWSKA A, BASLE MF, CHAPPARD D, MABILLEAU G: Thiazolidinediones induce osteocyte apoptosis by a G protein-coupled receptor 40-dependent mechanism. J Biol Chem 287: 23517-23526, 2012.

MOAYERI A, MOHAMADPOUR M, MOUSAVI SF, SHIRZADPOUR E, MOHAMADPOUR S, AMRAEI M: Fracture risk in patients with type 2 diabetes mellitus and possible risk factors: a systematic review and metaanalysis. Ther Clin Risk Manag 13: 455-468, 2017. 
MOLINUEVO MS, SCHURMAN L, MCCARTHY AD, CORTIZO AM, TOLOSA MJ, GANGOITI MV, ARNOL V, SEDLINSKY C: Effect of metformin on bone marrow progenitor cell differentiation: In vivo and in vitro studies. J Bone Mineral Res 25: 211-221, 2010.

MONAMI M, CRESCI B, COLOMBINI A, PALA L, BALZI D, GORI F, CHIASSERINI V, MARCHIONNI N, ROTELLA CM, MANNUCCI E: Bone fractures and hypoglycemic treatment in type 2 diabetic patients: a case-control study. Diabetes Care 31: 199-203, 2008.

MONAMI M, DICEMBRINI I, ANTENORE A, MANNUCCI E: Dipeptidyl peptidase-4 inhibitors and bone fractures: a meta-analysis of randomized clinical trials. Diabetes Care 34: 2474-2476, 2011.

NAOT D, CORNISH J: The role of peptides and receptors of the calcitonin family in the regulation of bone metabolism. Bone 43: 813-818, 2008.

NAPOLI N, PANNACCIULLI N, VITTINGHOFF E, CRITTENDEN D, YUN J, WANG A, WAGMAN R, SCHWARTZ AV: Effect of denosumab on fasting glucose in women with diabetes or prediabetes from the FREEDOM trial. Diabetes Metab Res Rev 34: e2991, 2018.

NAUCK MA, DEL PRATO S, MEIER JJ, DURÁN-GARCÍA S, ROHWEDDER K, ELZE M, PARIKH SJ: Dapagliflozin versus glipizide as add-on therapy in patients with type 2 diabetes who have inadequate glycemic control with metformin: a randomized, 52-week, double-blind, active-controlled noninferiority trial. Diabetes Care 34: 2015-2022, 2011.

NAZRUN AS, TZAR MN, MOKHTAR SA, MOHAMED IN: A systematic review of the outcomes of osteoporotic fracture patients after hospital discharge: morbidity, subsequent fractures, and mortality. Ther Clin Risk Manag 10: 937-948, 2014.

PALERMO A, D'ONOFRIO L, EASTELL R, SCHWARTZ AV, POZZILLI P, NAPOLI N: Oral anti-diabetic drugs and fracture risk, cut to the bone: safe or dangerous? A narrative review. Osteoporos Int 26: 2073-2089, 2015.

PAUL T, THOMAS N: Impact of oral antidiabetic agents on bone metabolism. Indian J Med Res141: 385-388, 2015.

PRAMOJANEE SN, PHIMPHILAI M, CHATTIPAKORN N, CHATTIPAKORN SC: Possible roles of insulin signaling in osteoblasts. Endocrine Res 39: 144-151, 2014.

QUANDT SA, STAFFORD JM, BELL RA, SMITH SL, SNIVELY BM, ARCURY TA: Predictors of falls in a multiethnic population of older rural adults with diabetes. J Gerontol A Biol Sci Med Sci 61: 394-398, 2006.

RAŠKA I Jr, RAŠKOVÁ M, ZIKÁN V, ŠKRHA J: Body composition is associated with bone and glucose metabolism in postmenopausal women with type 2 diabetes mellitus. Physiol Res 66: 99-111, 2017.

ROSENSTOCK J, AGGARWAL N, POLIDORI D, ZHAO Y, ARBIT D, USISKIN K, CAPUANO G, CANOVATCHEL W: Dose-ranging effects of canagliflozin, a sodium-glucose cotransporter 2 inhibitor, as add-on to metformin in subjects with type 2 diabetes. Diabetes Care 35: 1232-1238, 2012.

RUSSO GT, GIANDALIA A, ROMEO EL, NUNZIATA M, MUSCIANISI M, RUFFO MC, CATALANO A, CUCINOTTA D: Fracture risk in type 2 diabetes: current perspectives and gender differences. Int $J$ Endocrinol 2016: 1615735, 2016.

SEDLINSKY C, MOLINUEVO MS, CORTIZO AM, TOLOSA MJ, FELICE JI, SBARAGLINI ML, SCHURMAN L, MCCARTHY AD: Metformin prevents anti-osteogenic in vivo and ex vivo effects of rosiglitazone in rats. Eur J Pharmacol 668: 477-485, 2011.

SCHWARTZ AV: Diabetes and Metabolism of Bone. In: ENDO 2017: Meet-The-Professor Endocrine Case Management, LEAHY J, DANOFF A (eds), Washington DC: 2017, p. 63-65.

SCHWARTZ AV, HILLIER TA, SELLMEYER DE, RESNICK HE, GREGG E, ENSRUD KE, SCHREINER PJ, MARGOLIS KL, CAULEY JA, NEVITT MC, BLACK DM, CUMMINGS SR: Older women with diabetes have a higher risk of falls: a prospective study. Diabetes Care 25: 1749-1754, 2002.

SCHWARTZ AV, PAVO I, ALAM J, DISCH DP, SCHUSTER D, HARRIS JM, KREGE JH: Teriparatide in patients with osteoporosis and type 2 diabetes. Bone 91: 152-158, 2016.

SCHWARTZ AV, VITTINGHOFF E, SELLMEYER DE, FEINGOLD KR, DE REKENEIRE N, STROTMEYER ES, SHORR RI, VINIK AI, ODDEN MC, PARK SW, FAULKNER KA, HARRIS TB: Diabetes-related complications, glycemic control, and falls in older adults. Diabetes Care 31: 391-396, 2008.

STARUP-LINDE J, VESTERGAARD P: Biochemical bone turnover markers in diabetes mellitus - A systematic review. Bone 82: 69-78, 2016. 
SU B, SHENG H, ZHANG M, BU L, YANG P, LI L, LI F, SHENG C, HAN Y, QU S, WANG J: Risk of bone fractures associated with glucagon-like peptide-1 receptor agonists' treatment: a meta-analysis of randomized controlled trials. Endocrine 48: 107-115, 2015.

SUNDARARAGHAVAN V, MAZUR MM, EVANS B, LIU J, EBRAHEIM NA: Diabetes and bone health: latest evidence and clinical implications. Ther Adv Musculoskelet Dis 9: 67-74, 2017.

TAHRANI AA, BARNETT AH, BAILEY CJ: SGLT inhibitors in management of diabetes. Lancet Diabetes Endocrinol 1: 140-151, 2013.

TAYLOR SI, BLAU JE, ROTHER KI: Possible adverse effects of SGLT2 inhibitors on bone. Lancet Diabetes Endocrinol 3: 8-10, 2015.

THRAILKILL KM, LUMPKIN CK, BUNN RC, KEMP SF, FOWLKES JL: Is insulin an anabolic agent in bone? Dissecting the diabetic bone for clues. Am J Physiol Endocrinol Metab 289: E735-E745, 2005.

TILLING LM, DARAWIL K, BRITTON M: Falls as a complication of diabetes mellitus in older people. J Diabetes Complications 20: 158-162, 2006.

TORRES-COSTOSO A, POZUELO-CARRASCOSA DP, ÁLVAREZ-BUENO C, FERRI-MORALES A, MIOTA IBARRA J, NOTARIO-PACHECO B, MARTÍNEZ-VIZCAÍNO V: Insulin and bone health in young adults: The mediator role of lean mass. PLoS ONE 12: e0173874, 2017.

TUCKER ME: Sulfonylureas may up fracture risk in diabetes, along with TZDs. Medscape 2014.

VESTERGAARD P: Discrepancies in bone mineral density and fracture risk in patients with type 1 and type 2 diabetes-a meta-analysis. Osteoporos Int 18: 427-444, 2007.

VESTERGAARD P, REJNMARK L, MOSEKILDE L: Are antiresorptive drugs effective against fractures in patients with diabetes? Calcif Tissue Int 88: 209-214, 2011.

VESTERGAARD P, REJNMARK L, MOSEKILDE L: Diabetes and its complications and their relationship with risk of fractures in type 1 and 2 diabetes. Calcif Tissue Int 84: 45-55, 2009.

VESTERGAARD P, REJNMARK L, MOSEKILDE L: Relative fracture risk in patients with diabetes mellitus, and the impact of insulin and oral antidiabetic medication on relative fracture risk. Diabetologia 48: 1292-1299, 2005.

WATTS NB, BILEZIKIAN JP, USISKIN K, EDWARDS R, DESAI M, LAW G, MEININGER G: Effects of canagliflozin on fracture risk in patients with type 2 diabetes mellitus. The J Clin Endocrinol and Metab 101: 157-166, 2016.

WHALLEY NM, PRITCHARD LE, SMITH DM, WHITE A: Processing of proglucagon to GLP-1 in pancreatic alphacells: is this a paracrine mechanism enabling GLP-1 to act on beta-cells? J Endocrinol 211: 99-106, 2011.

YAMADA C, YAMADA Y, TSUKIYAMA K, YAMADA K, UDAGAWA N, TAKAHASHI N, TANAKA K, DRUCKER DJ, SEINO Y, INAGAKI N: The murine glucagon-like peptide-1 receptor is essential for control of bone resorption. Endocrinol 149: 574-579, 2008.

YAVROPOULOU M, MOUSIOLIS A, KOLOKOURI V, KOLIMPIANAKI P, DIMITRIOU A, PAPALEXIS P, DANIILIDIS M, KOTSA K: Anti-diabetic treatment as an additional factor in a FRAX based evaluation of osteoporotic fracture risk. Endocr Abstr 37: EP300, 2015.

ZHAO Y, ZHANG S, ZENG D, XIA L, LAMICHHANE A, JIANG X, ZHANG F: rhPDGF-BB promotes proliferation and osteogenic differentiation of bone marrow stromal cells from streptozotocin-induced diabetic rats through ERK Pathway. BioMed Res Int 2014: 637415, 2014.

ZHUKOUSKAYA VV, SHEPELKEVICH AP, CHIODINI I: Bone health in type 1 diabetes: Where we are now and how we should proceed. Adv Endocrinol 2014: 12, 2014.

ZINMAN B, HAFFNER SM, HERMAN WH, HOLMAN RR, LACHIN JM, KRAVITZ BG, PAUL G, JONES NP, AFTRING RP, VIBERTI G, KAHN SE: Effect of rosiglitazone, metformin, and glyburide on bone biomarkers in patients with type 2 diabetes. J Clin Endocrinol Metab 95: 134-142, 2010.

ZOFKOVA I: Bone tissue as a systemic endocrine regulator. Physiol Res 64: 439-445, 2015.

ZOFKOVA I, BLAHOS J: New molecules modulating bone metabolism - new perspectives in the treatment of osteoporosis. Physiol Res 66 (Suppl. 3): S341-S347, 2017. 